\title{
Simplified laparoscopic wedge resection for gastrointestinal stromal tumors adjacent to the esophagogastric junction or posterior fundus wall
}

\author{
Francisco Berrospi-Espinoza, Ramiro M. Fernández-Placencia, Eloy Ruiz-Figueroa \\ Department of Abdominal Surgery, Instituto Nacional de Enfermedades Neoplásicas “Dr. Eduardo Cáceres Graziani”, Lima, Peru \\ Correspondence to: Ramiro M. Fernández-Placencia. 2520 E Angamos Av. Of. 216. Surquillo, Lima 034. Lima, Peru. Email: ramirofp02@gmail.com.
}

\begin{abstract}
Gastrointestinal stromal tumors (GIST) are very infrequent neoplasms of the gastrointestinal tract, most commonly located in the stomach and small intestine. Due to the rising incidence of these tumors, a wide array of surgical approaches for diverse scenarios of this disease is currently being explored. Small GISTs in unfavorable locations of the stomach like those near the esophagogastric junction (EGJ) have different techniques for local resection such as: intragastric, transgastric, combined endoscopic-laparoscopic in order to preserve function and oncological principles. Many different minimally-invasive techniques have been proposed for these. A simplified laparoscopic approach, especially for those neoplasms located in the posterior wall adjacent to the EGJ is presented.
\end{abstract}

Keywords: Gastrointestinal stromal tumors (GIST); minimally invasive surgery; gastric fundus

Received: 08 October 2018; Accepted: 30 October 2018; Published: 06 November 2018.

doi: $10.21037 /$ jovs.2018.11.02

View this article at: http://dx.doi.org/10.21037/jovs.2018.11.02

\section{Introduction}

Gastrointestinal stromal tumors (GIST) are very infrequent neoplasms of the gastrointestinal tract (1), most commonly located in the stomach and small intestine (2). Because of the rising incidence of these tumors (3), a wide array of surgical approaches for diverse scenarios of this disease are currently being explored.

Thebiologicbehavior ofGIST is thatofan expansivegrowth rather than infiltrative and lymphatic invasion is rare (4). For this reason, the surgeon can perform a curative and safe surgery with a wedge resection. Oncologic outcomes are proven to be equal to open surgery with the intrinsic benefits of minimally-invasive approaches $(5,6)$.

For tumors restricted to the stomach, the open approach has been for decades the standard technique for resection $(3,7)$. In the last decade, laparoscopic surgery has gained acceptance for the treatment of GIST; initially limited to small tumors according to ESMO, NCCN guidelines (8-10) and more recently for larger tumors. Nowadays, NCCN Guidelines consider that laparoscopic resection should be offered in favorable locations (anterior wall, greater curvature of the stomach) and performed by experienced surgeons (3).

Ongoing evidence is demonstrating the role of minimally invasive surgery with lager tumor sizes (11-13) and unfavorable locations. Privette et al. proposed a practical classification for GISTs located in the stomach, those in the fundus are type I, those mainly in the antrum are type II and those near the esophagogastric junction are type III (14). Small GISTs in the latter have different techniques for local resection such as: intragastric, transgastric, combined endoscopic-laparoscopic in order to preserve function and oncological principles.

In the presence of a tumor located near the esophagogastric junction and specially those located in the posterior wall of the fundus a proximal gastrectomy [e.g., Merendino-Dillard procedure (15)] is usually indicated.

A laparoscopic approach, especially for those neoplasms located in the posterior wall adjacent to the EGJ is presented. The aim of this technique is to provide a simplified method that provides good oncologic and functional outcomes. 


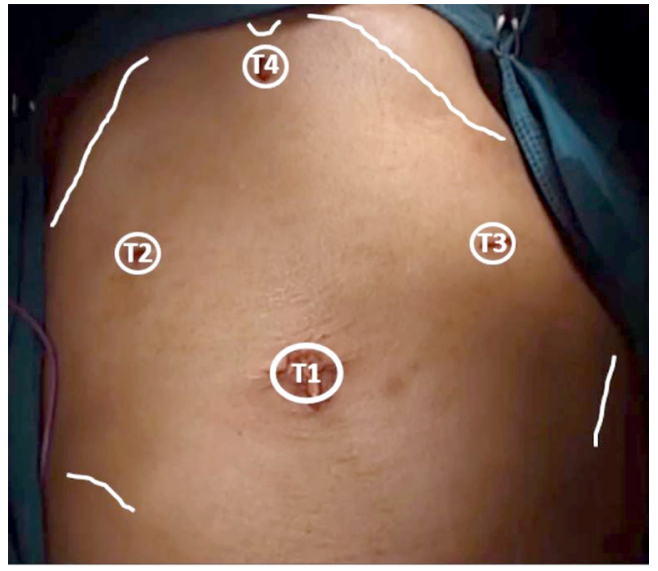

Figure 1 Trochar placement in the abdomen (T1) for $30^{\circ}$ laparoscope, (T2) for $5 \mathrm{~mm}$, (T3) and (T4) initially are $5 \mathrm{~mm}$ but can be replaced with a $12 \mathrm{~mm}$ trochar for stapler use.

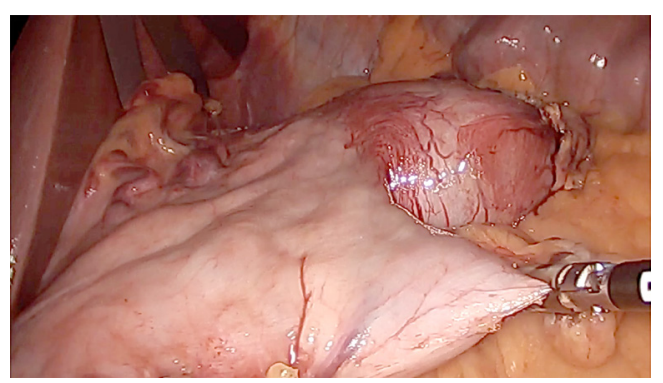

Figure 2 Non-tumoral tissue is grasped during the procedure to avoid tumoral rupture.

\section{Operative technique (for visual details, please refer to Online Resource)}

With the patient lying supine, the surgeon stands to the right of the patient and the assistant to the surgeon's right. The monitor is placed to the left shoulder of the patient. Closed pneumoperitoneum is started through the umbilicus, pressure is set at $12 \mathrm{mmHg}$. After this the position is set $20^{\circ}$ head-up tilt and $15^{\circ}$ right rotation in order to achieve a wide intra-abdominal workspace. A $10-\mathrm{mm}$ trocar is inserted through the umbilicus (T1) and a $30^{\circ}$ scope is introduced and diagnostic laparoscopy can be performed. $\mathrm{T} 2$ is placed in the right upper quadrant, T3 in the left upper quadrant and $\mathrm{T} 4$ in the sub-xiphoid region (Figure 1). T2 and T4 are used with the left hand and T3 for the right hand. If assistance is required the surgeon can use $\mathrm{T} 2$ and $\mathrm{T} 4$ and the assistant uses T3.

After diagnostic laparoscopy, the stomach is inspected

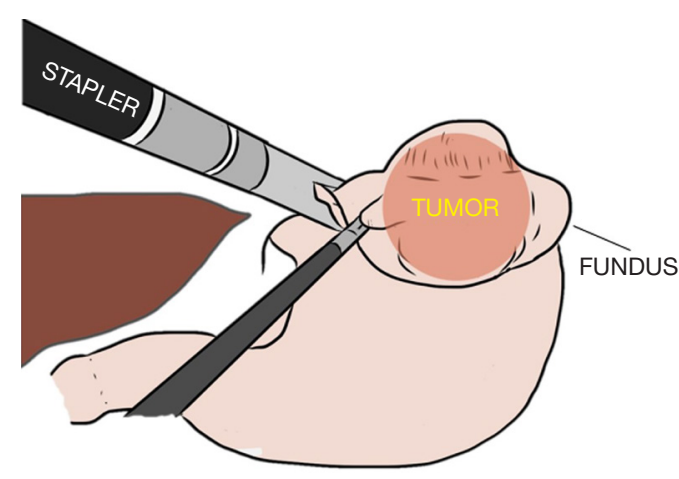

Figure 3 "Top to bottom" use of stapler through (T4). Resection margin is assured under direct vision and the tumor is rotated upfront.

to confirm the exact position of the tumor. The surgeon's left hand grasps the anterior gastric wall to expose the gastrocolic ligament and starts its division at the level of the gastroepiploic artery which is divided with a vessel sealer. Alternatively, ultrasonic or other bipolar shears can be used.

The dissection goes along the greater curvature by dividing the short gastric vessels exposing the posterior gastric wall. Once the tumor is visualized much care is taken in order to avoid direct manipulation and eventual capsule disruption. Traction must always be applied to the normal gastric wall (Figure 2). For complete freeing of the posterior wall of the gastric fundus, the surgeon's left hand switches to T3 for direct approach of the phrenogastric ligament and the posterior gastric vessels which are severed preventing tumor manipulation. During dissection special care should be taken to avoid entering the splenic hilum or tearing the spleen capsule.

When complete mobilization of the fundus is achieved, one of the $5-\mathrm{mm}$ trocar (either T3 or T4) are changed to a $12-\mathrm{mm}$ to introduce the $60 \mathrm{~mm}$ endoscopic linear stapler. For the first patient the sub xiphoid trocar (T3) was used for direct insertion of the stapler 1 or $2 \mathrm{~cm}$ at the left of the angle of Hiss to prevent narrowing the cardia (Figure 3). Two 60-mm cartridges were needed to complete the wedge resection from top to bottom. The stapled line in the stomach is inspected for adequate closure and hemostasis. No endoscopic control was needed. The specimen is retrieved in an endoscopic bag through the enlarged incision (less than $5 \mathrm{~cm}$ ) at T1. In the second patient, T4 was selected for the insertion of the linear stapler and the tumor was resected from bottom to top (Figure 4). In both cases resection margins of more than $1 \mathrm{~cm}$ were obtained. The $12-\mathrm{mm}$ and 
the enlarged incisions were closed using 1/0 polyglycolic acid (Figure 5).

\section{Comments}

This paper shows a novel operative technique for GISTs

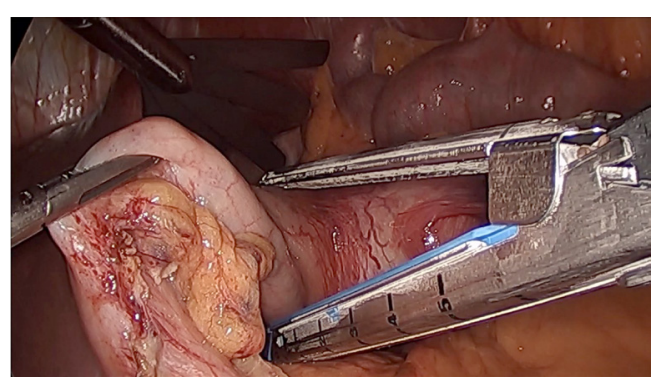

Figure 4 "Bottom to top" use of stapler through (T3). Resection margin is always checked under direct vision.

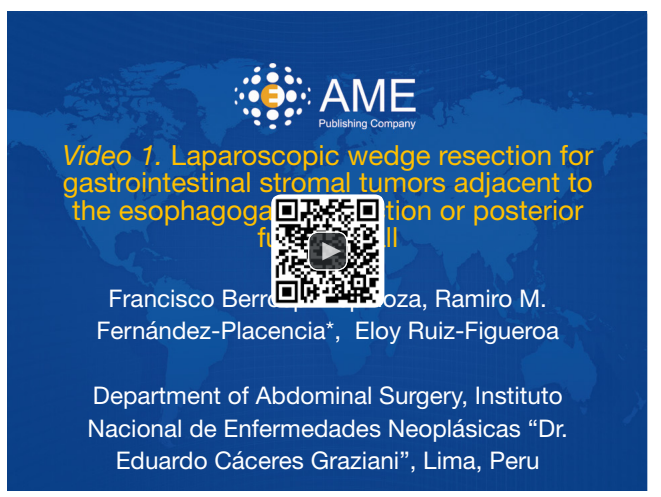

Figure 5 Laparoscopic wedge resection for gastrointestinal stromal tumors adjacent to the esophagogastric junction or posterior fundus wall (16). A simplified method with selective dissection of the upper third of the stomach.

Available online: http://www.asvide.com/article/view/28173 located near the EGJ according to the classification of Privette et al. (14), this laparoscopic approach for type I and type III lesions preserves the organ and function through a wedge resection. Both types were located near the EGJ.

There are various techniques for the surgical treatment of GISTs, from cooperative approaches which are described in the literature (17), including intragastric resection $(18,19)$, some of them require sophisticated equipment (20).

Reported laparoscopic techniques for this specific location are few, may be due to the complex location and this undoubtedly requires the best oncologic result with anatomic and functional preservation. This selective mobilization of the stomach has less use of trocars and dissection is made along the greater curvature which is important to provide adequate perfusion of the organ besides the requirements presented above. Counter-clockwise fundic rotation may ease the stapler use with even less manipulation of the tumor. This fundic rotation is opposite to the technique presented by Matsui et al. (21). Our technique is similar to that proposed by Maker (22) in terms of counter-clockwise rotation but there is lesser need of ports and staplers; likewise there was not endoscopic cooperation or traction sutures. Kiyozaki et al. propose the use of lifting stitches as well with less number of ports (23), currently a three-port technique is under development with lifting of the liver for better exposure.

Surgical treatments for GISTs in unfavorable locations must be continuously developed in order to achieve the best oncologic and functional outcomes. This technique proved to be useful in the treatment of tumors larger than $5 \mathrm{~cm}$, located in the posterior wall of the fundus near the EGJ and prevented a proximal gastrectomy with adequate margins. In terms of organ function, no reflux disease or stenosis is reported and the patients have adequate nutritional status (Table 1). Moreover, this type of resection respects the oncologic principle of notouch with no need to open the stomach and can become an option for surgeons who treat this neoplasm.

Table 1 Clinical, operative and pathologic characteristics (as presented in online resource)

\begin{tabular}{cccccccccccc}
\hline$N^{\circ}$ & Age & Sex & $\begin{array}{c}\text { Hospital stay } \\
\text { (days) }\end{array}$ & $\begin{array}{c}\text { Blood loss } \\
(\mathrm{cc})\end{array}$ & $\begin{array}{c}\text { Operative time } \\
(\mathrm{min})\end{array}$ & $\begin{array}{c}\text { Tumor size } \\
(\mathrm{cm})\end{array}$ & Surgical margins & $\begin{array}{c}\text { Follow-up } \\
\text { (months) }\end{array}$ & Complications & Recurrence \\
\hline 1 & 65 & Male & 6 & 50 & 185 & 5 & $\begin{array}{c}\text { Negative for } \\
\text { disease }\end{array}$ & 26 & None & None \\
2 & 55 & Female & 4 & 50 & 200 & 6 & $\begin{array}{c}\text { Negative for } \\
\text { disease }\end{array}$ & 34 & None & None \\
\hline
\end{tabular}




\section{Acknowledgments}

Operative technique presented as a video and Best Video Award Winner at the 12 th International Gastric Cancer Congress - Beijing 2017.

Funding: None.

\section{Footnote}

Conflicts of Interest: All authors have completed the ICMJE uniform disclosure form (available at http://dx.doi. org/10.21037/jovs.2018.11.02). The authors have no conflicts of interest to declare.

Ethical Statement: The authors are accountable for all aspects of the work in ensuring that questions related to the accuracy or integrity of any part of the work are appropriately investigated and resolved. All procedures performed in studies involving human participants were in accordance with the ethical standards of the institutional and/or national research committee(s) and with the Helsinki Declaration (as revised in 2013). All patients gave informed consent for data according to the principles of the Helsinki Declaration. The Ethics Committee of the hospital approved the study protocol.

Open Access Statement: This is an Open Access article distributed in accordance with the Creative Commons Attribution-NonCommercial-NoDerivs 4.0 International License (CC BY-NC-ND 4.0), which permits the noncommercial replication and distribution of the article with the strict proviso that no changes or edits are made and the original work is properly cited (including links to both the formal publication through the relevant DOI and the license). See: https://creativecommons.org/licenses/by-nc-nd/4.0/.

\section{References}

1. Judson I, Demetri G. Advances in the treatment of gastrointestinal stromal tumours. Ann Oncol 2007;18 Suppl 10:x20-4.

2. Corless CL. Gastrointestinal stromal tumors: what do we know now? Mod Pathol 2014;27 Suppl 1:S1-16.

3. Demetri GD, von Mehren M, Antonescu CR, et al. NCCN Task Force report: update on the management of patients with gastrointestinal stromal tumors. J Natl Compr Canc Netw 2010;8 Suppl 2:S1-41; quiz S42-4.

4. DeMatteo RP, Lewis JJ, Leung D, et al. Two hundred gastrointestinal stromal tumors: recurrence patterns and prognostic factors for survival. Ann Surg 2000;231:51-8.

5. Pelletier JS, Gill RS, Gazala S, et al. A Systematic Review and Meta-Analysis of Open vs. Laparoscopic Resection of Gastric Gastrointestinal Stromal Tumors. J Clin Med Res 2015;7:289-96.

6. Cao F, Li A, Li J, et al. Feasibility and safety of laparoscopic resection for gastric GISTs larger than $5 \mathrm{~cm}$ : Results from a prospective study. Oncol Lett 2015;10:2081-6.

7. Blay JY, Bonvalot S, Casali P, et al. Consensus meeting for the management of gastrointestinal stromal tumors. Report of the GIST Consensus Conference of 20-21 March 2004, under the auspices of ESMO. Ann Oncol 2005;16:566-78.

8. Casali PG, Jost L, Reichardt P, et al. Gastrointestinal stromal tumors: ESMO clinical recommendations for diagnosis, treatment and follow-up. Ann Oncol 2008;19 Suppl 2:ii35-8.

9. Demetri GD, Benjamin RS, Blanke CD, et al. NCCN Task Force report: management of patients with gastrointestinal stromal tumor (GIST)--update of the NCCN clinical practice guidelines. J Natl Compr Canc Netw 2007;5 Suppl 2:S1-29; quiz S30.

10. Nishida T, Hirota S, Yanagisawa A, et al. Clinical practice guidelines for gastrointestinal stromal tumor (GIST) in Japan: English version. Int J Clin Oncol 2008;13:416-30.

11. Hsiao CY, Yang CY, Lai IR, et al. Laparoscopic resection for large gastric gastrointestinal stromal tumor (GIST): intermediate follow-up results. Surg Endosc 2015;29:868-73.

12. Cui JX, Gao YH, Xi HQ, et al. Comparison between laparoscopic and open surgery for large gastrointestinal stromal tumors: A meta-analysis. World J Gastrointest Oncol 2018;10:48-55.

13. Lin J, Huang C, Zheng C, et al. Laparoscopic versus open gastric resection for larger than $5 \mathrm{~cm}$ primary gastric gastrointestinal stromal tumors (GIST): A size-matched comparison. Surg Endosc 2014;28:2577-83.

14. Privette A, McCahill L, Borrazzo E, et al. Laparoscopic approaches to resection of suspected gastric gastrointestinal stromal tumors based on tumor location. Surg Endosc 2008;22:487-94.

15. Merendino KA, Dillard DH. The Concept of Sphincter Substitution by an Interposed Jejunal Segment for Anatomic and Physiologic Andomalities at the Esophagogastric Junction. Ann Surg 1955;142:486-506.

16. Berrospi-Espinoza F, Fernández-Placencia RM, 
Ruiz-Figueroa E. Laparoscopic wedge resection for gastrointestinal stromal tumors adjacent to the esophagogastric junction or posterior fundus wall. Asvide 2018;5:840. Available online: http://www.asvide.com/ article/view/28173

17. Shingaki S, Kanemaru S, Oda Y, et al. Distant metastasis and survival of adenoid cystic carcinoma after definitive treatment. J Oral Maxillofac Surgery, Med Pathol 2014;26:312-6.

18. Kanehira E, Kamei A, Umezawa A, et al. Long-term outcomes of percutaneous endoscopic intragastric surgery in the treatment of gastrointestinal stromal tumors at the esophagogastric junction. Surg Endosc 2016;30:2036-42.

19. Warsi AA, Peyser PM. Laparoscopic resection of gastric GIST and benign gastric tumours: Evolution of a new technique. Surg Endosc 2010;24:72-8.

doi: $10.21037 /$ jovs.2018.11.02

Cite this article as: Berrospi-Espinoza F, FernándezPlacencia RM, Ruiz-Figueroa E. Simplified laparoscopic wedge resection for gastrointestinal stromal tumors adjacent to the esophagogastric junction or posterior fundus wall. J Vis Surg 2018;4:231.
20. Hiki N, Yamamoto Y, Fukunaga T, et al. Laparoscopic and endoscopic cooperative surgery for gastrointestinal stromal tumor dissection. Surg Endosc 2008;22:1729-35.

21. Matsui H, Nabeshima K, Okamoto Y, et al. Fundic rotation technique: A useful procedure for laparoscopic exogastric resection of gastric submucosal tumors located on the posterior wall near the esophagogastric junction. Tokai J Exp Clin Med 2011;36:152-8.

22. Maker AV. A Technique for Laparoendoscopic Resection of Posterior Fundic Gastric GISTs Without Need for a Gastrotomy. Ann Surg Oncol 2013;20:4238.

23. Kiyozaki H, Saito M, Chiba H, et al. Laparoscopic wedge resection of the stomach for gastrointestinal stromal tumor (GIST): Non-touch lesion lifting method. Gastric Cancer 2014;17:337-40. 